\title{
STRATEGI PENGEMBANGAN KUTA LOMBOK SEBAGAI DESTINASI PARIWISATA
}

\author{
Ander Sriwi \\ I Nyoman Sudiarta \\ Ni Putu Eka Mahadewi \\ Email : undersriwi@gmail.com \\ PS. S1 Industri Perjalanan Wisata \\ Fakultas Pariwisata UNUD
}

\begin{abstract}
ABSTRAK
Penelitian ini bertujuan untuk mengetahui potensi-potensi wisata yang dimiliki oleh destinasi pariwisata Kuta Lombok, kemudian akan dirumuskan strategi yang dapat diterapkan di destinasi pariwisata Kuta Lombok sehingga membantu proses pengembangannya menjadi lebih optimal. Dalam penelitian ini teknik pengumpulan data menggunakan metode obsevasi artinya melakukan pengamatan langsung di Kuta Lombok (lokasi penelitian), wawancara mendalam artinya bertanya langsung kepada informan yang dipilih sudah dipilih, dan dokumenasi. Teknik penentuan informan dengan menggunakan metode purposive sampling, sedangkan untuk teknis analisis data dalam penelitian ini menggunakan analisis deskriftif kualitatif dan analisis SWOT. Hasil yang didapatkan melalui analisis deskriftif kualitatif dan analisis SWOT adalah bahwa potensi-potensi yang dimiliki oleh Kuta Lombok merupakan potensi yang harus dikembangkan, karena destinasi pariwisata Kuta Lombok memiliki potensi yang sangat potensial. Potensi wisata yang ada seperti, pemandangan laut dan pantainya, pemandangan matahari terbit dan matahari terbenam pemandangan alam yang meliputi perbukitan yang berbaris dan hijau. Sedangkan potensi sosial budaya yang terdapat di Kuta Lombok adalah terdiri dari keunikan tradisi dan budaya masyarakat setempat seperti upacara adat sasak, kesenian radisional, tradisi presean dan Bau Nyale. Melihat potensi-potensi yang dimiliki oleh Kuta Lombok berdasarkan hasil dari analisis AWOT dalam pengembangan destinasi pariwisata Kuta Lombok terdapat beberapa strategi yang bisa dilakukan dalam pengembangan destinasi pariwisata Kuta Lombok, strategi-strategi tersebut yaitu: strategi pengembangan daya tarik wisata dan strategi pengembangan daya tarik wisata yang dihasilkan oleh strategi strength-opportunity ( $\mathrm{S}-\mathrm{O}$ ), strategi peningkatan keamanan dan kenyamanan yang dihasilkan oleh trategi strength-threat (S-T), strategi peningkatan kualitas lingkungan dan strategi promosi destinsi pariwisatayang dihasilkan oleh strategi weakness-opportunity (W-O), strategi pengembangan sumber daya manusia yang dihasilkan oleh ytrategi weakness-threat (W-T).
\end{abstract}

\section{Kata Kunci : Strategi pengembangan Kuta Lombok sebagai dstinasi pariwisata}

\section{LATAR BELAKANG}

Perkembangan pariwisata di Indonesia saat ini semakin meningakat seiring adanya keinginan pemerintah Indonesia yang menargetkan kunjungan 20 juta wisatawan pada tahun 2020. Untuk mewujudkan target kunjungan tersebut, pemerintah saat ini tengah gencar melakukan promosi wisata di berbagai Negara salah satunya di New Delhi, India dalam acara Word Culture Festival (WCF), (www.kemenpar.go.id). Selain melakukan promosi, dalam mendukung perkembangan pariwisata Indonesia. Pemerintah tengah melakukan percepatan pembangunan terutama di bidang pariwisata yang sudah lakukan di berbagai daerah, diantaranya destinasi pariwisata Kuta Lombok yang terletak di Kabupaten Lombok Tengah. 
Destinasi pariwisata Kuta Lombok adalah destinasi pariwisata yang banyak dikunjungi wisatawan nusantara maupun wistawan mancanegara, keindahan alamnya yang masih alami dan hijau, keindahan laut dan pantainya serta pemandangan maahari terbit dan matahari terbenam. Potensi-potensi yang dimiliki oleh Kuta Lombok seperti keindahan alamnya, keindahan pantainya dan pemandangan matahari terbit dan matahari terbenam, serta tradisi masyarakatnya merupakan potensi yang harus dikembangkan sehingga nantinya diharapkan mampu menarik minat wisatawan berkunjung ke Kuta Lombok.

Meskipun Kuta Lombok telah tersedia berbagai jenis daya tarik wisata yang beragam, Tetapi ada beberapa masalah yang masih perlu diperhatikan lebih lanjut oleh pemerintah seperti pengembangan destinasi pariwisata Kuta Lombok yang kurang maksimal sehingga perkembangan Kuta Lombok masih belum terlihat secara signifikan. Berdasarkan permasalahan tersebut, peneliti menarik untuk menganalisis bagaimana strategi yang bisa dilakukan atau diterapkan di destinasi pariwisata Kuta Lombok sehingga pengembangan kepariwisataan Kuta Lombok dapat berjalan secara optimal.

\section{METODE}

\section{Jenis dan Sumber Data}

Dalam penelitian ini jenis data yang digunakan adalah jenis data kualitatif dan data kuantitatif, sedangkan sumber data yang digunakan adalah sumber data primer dan sumber data sekunder.

\section{Teknik Pengumpulan data}

Dalam penelitian ini teknik pengumpulan data menggunakan meode observasi atau pengamatan langsung di lokasi penelitian, wawancara mendalam (in-deph interview) yaitu peneliti bertanya langsung kepada informan yang dipilih, dan studi dokumen (dokumentasi).

\section{Teknik Penentuan Informan}

Sugiyono (2009:221) mengemukakan bahawa dalam suatu penelitian penentuan informan sangan mempengaruhi hasil dari penelitian tesebut terlebih lagi penelitian kualitatif, karena penentuan informan berfungsi untuk mendapatkan informasi yang maksimum.
Maka dalam penelitian ini teknik penentuan informan menggunakan teknik purposive sampling.

Teknik Analisis Data

Teknik analisis data yang digunakan dalam penelitia ini adalah analisis deskriftif kualitatif dan analisis SWOT.

HASIL

\section{Potensi dan Daya Tarik Wisata Kuta Lombok}

Dalam penelitian ini terdapat dua potensi wisata yang dimiliki oleh Kuta Lombok yang dapat mendorong perkembangan Kuta Lombok menjadi destinasi pariwisata yaitu potensi alam dan potensi sosial budaya. Destinasi pariwisata Kuta Lombok memiliki berbagai jenis daya tarik wisata yang beragam, mulai dari daya tarik wisaya alam maupun sosial budaya. Keindahan laut dan pantai, perbukitan, pemandangan matahari terbit dan matahari terbenam merupakan potensi alam Kuta Lombok yang sangagt mendukung pengembangan destinasi pariwisata Kuta Lombok. Keindahan alam Kuta Lombok merupakan potensi dan daya tarik wisata yang bisa menarik minat wisatawan untuk berkunjung ke Kuta Lombok baik wisatawan mancanegara maupun wisatawan nusantara. Sedangkan untuk potensi sosial budaya terdiri dari acara Bau Nyale yang biasa disemarakan dengan bernagai atraksi budaya seperti pawai budaya, kerajinan dan kesenian taradisional, selanjutna akan diadakan lomba pacuan kuda, dan juga presean.

Program Pengembangan Destinasi Pariwisata Kuta Lombok dari Strategi StrengthOpportunity (S-O)

Dari strategi ada beberapa strategi yang di dapatkan yang bisa dilakukan dalam pengembangan destinasi pariwisata Kuta Lombok, strategi tersebut adalah;

1. Strategi pengembangan destinasi pariwisata, dalam mendukung pengembangan destinasi pariwisata Kuta Lombok sangat perlu dilakukan terlebih dahulu adalah mengembangkan potensi-potensi yang sudah ada, dalam hal ini ada beberapa program yang bisa di aplikasikan untuk mengembangkan potensi wisata Kuta Lombok seperti, mengelompokkan daya tarik wisata terlebih dahulu seperti potensi 
alam dan potensi sosial budaya. Selanjutnya perlu dilakukan juga pembuatan wisata unggulan yang nantinya akan menjadi salah satu andalan atau menjadi icon Kuta Lombok

2. Strategi pengembangan destinasi pariwisata, dalam pengembangan destinasi pariwisata Kuta Lombok, ada beberapa program yang bisa diterapkan untuk mengembangkan destinasi pariwisata Kuta Lombok, programprogram tersebut antara lain:

a. Pertama, perlu adanya pengembangan sarana dan prasarana di Kuta Lombok beserta infrastruktur dalam mendukung jalanya aktivitas kepariwisata.

b. Kudua, yaitu dengan penambahan fasilitas pengelola pariwisata lainnya seperti; pusat layanan informasi yang biasa disebut Tourism Information Center, dan lebih memperhatikan masalah keamanan dan kenyamanan wisatawan yang berkunjung dengan meningkatkan keamanan dan kenyamanan destinasi pariwisata.

c. Perlu adanya pembangunan akomodasi pariwisata seperti; program pembangunan toilet umum, dan program pembuatan tempat-tempat sampah yang ramah lingkungan

Program pengembangan Destinasi Pariwisata Kuta Lombok dari Strategi Strength-Threat (S-T)

Strategi Weakness-Opportunity, strategi ini menghasilkan strategi peningkatan keamanan dan kenyamanan destinasi pariwisata Kuta Lombok, untuk mengatasi hal tersebut, ada beberapa program yang bisa dilakukan antara lain;

1. Dalam meningkatkan keamanan dan kenyamanan destinasi pariwisata Kuta Lombok selain melakukan kejasama dengan pemerintah, pihak kepolisian untuk mengatasi hal tersebut perlu juga dukungan dari masyarakat ataupun pelaku wisata lainnya.

2. Program Peningkatan dan Memaksimalkan kerja Satpam Pantai.

Program Pengembangan Destinasi Pariwisata Kuta Lombok dari Strategi WeaknessOpportunity (W-O)

Strategi Weakness-Opportuniy, dari strategi ini ditemukan 2 (dua) yaitu strategi promosi destinasi pariwisata dan strategi pengembangan kualitas lingkungan.

1. Strategi peningkatan kualitas lingkungan, dalam meningkatkan kualitas lingkungan destinasi pariwisata Kuta Lombok beberapa hal yang perlu dilakukan untuk menjadikan destinasi pariwisata Kuta Lombok lebih baik adalah yang pertama dengan mengadakan kegiatan bersih pantai, hal ini bisa dilakukan dengan mengajak masyarakat setempat khususnya Desa Kuta maupun pelaku pariwisata, mengadakan penyuluhan tentang membangun dan meningkatkan kesadaran masyarakat akan pendingnya budaya bersih.

2. Strategi promosi destinasi pariwisata, untuk mempromosikan destinasi pariwisata Kuta Lombok ada beberapa program yang harus dilakukan yaitu, mempromosikan destinasi pariwisata Kuta Lombok dengan menggunakan media cetak dan bisa juga menggunakan elektronik, serta cara lainnya seperti Dinas Pariwisata maupu kepemerintahan lainnya.

Program Pengembangan Destinasi Pariwisata Kuta Lombok dari Strategi Weakness-Threat (W-T)

Strategi Weakness-Threat (W-T), dengan meminimalkan dan juga menghindari semua ancaman strategi ini menghasilkan beberapa strategi yang bisa dilakukan dalam pengembangan destinasi pariwisata Kuta Lombok salah satunya yaitu trategi pengembangan sumber daya manusia, artinya kualitas sumber daya manusia perlu ditingkatkan agar dapat berpartisipasi dan berkecimpung langsung dalam pengembangan destinasi pariwisata Kuta Lombok. Dari strategi tersebut beberapa program yang perlu dilakukan untuk mengatasi masalah tersebut misalnya, dengan mengadakan pelatihan atau pendidikan pemandu wisata (Guide).

\section{PEMBAHASAN}

Strategi Pengembangan Destinasi Parwisata Kuta Lombok

Untuk medapatkan strategi yang bisa dilakuka dalam pengembangan destinasi pariwisata Kuta Lombok, terlebih dahulu menguraikan dalam bentuk tabel terkait dengan faktor internal maupun eksternalnya. Kemudian langkah selanjutnya adalah menjelaskan atau 
memberikan ulasan dalam bentuk tabel matriks SWOT untuk merumuskan strategi yang bisa diterapkan dalam pengembangan destinasi pariwisata Kuta Lombok.

Tabel: 1.1 Matriks Analisis SWOT

\begin{tabular}{|c|c|c|}
\hline EFAS & $\begin{array}{l}\text { Strengths (S) } \\
\text { Tentukan } \\
\text { faktor } \\
\text { kekuatan } \\
\text { internal }\end{array}$ & $\begin{array}{l}\text { Weaknesses } \\
\quad \text { (W) } \\
\text { Tentukan } \\
\text { faktor } \\
\text { kelemahan } \\
\text { internal }\end{array}$ \\
\hline $\begin{array}{l}\text { Opportunitie } \\
\quad \boldsymbol{s}(\mathbf{O}) \\
\text { Tentukan } \\
\text { faktor } \\
\text { peluang } \\
\text { eksternal }\end{array}$ & $\begin{array}{l}\text { Strategi S-O } \\
\text { Ciptakan } \\
\text { strategi yang } \\
\text { menggunakan } \\
\text { kekuatan } \\
\text { untuk } \\
\text { memanfaatka } \\
\text { n peluang }\end{array}$ & $\begin{array}{l}\text { Strategi W-O } \\
\text { Ciptakan } \\
\text { strategi yang } \\
\text { meminimalka } \\
\text { n kelemahan } \\
\text { untuk } \\
\text { memanfaatkan } \\
\text { peluang }\end{array}$ \\
\hline $\begin{array}{l}\text { Threats (T) } \\
\text { Tentukan } \\
\text { faktor } \\
\text { ancaman } \\
\text { eksternal }\end{array}$ & $\begin{array}{l}\text { Strategi S-T } \\
\text { Ciptakan } \\
\text { strategi yang } \\
\text { menggunakan } \\
\text { kekuatan } \\
\text { untuk } \\
\text { mengatasi } \\
\text { ancaman } \\
\end{array}$ & $\begin{array}{l}\text { Strategi W-T } \\
\text { Ciptakan } \\
\text { strategi } \\
\text { meminimalka } \\
\text { n kelemahan } \\
\text { dan } \\
\text { menghindari } \\
\text { ancaman }\end{array}$ \\
\hline
\end{tabular}

Sumber: Diadaptasi dari Rangkuti, 2009:31

1. Strategi Strength-Opportunity (S-O), strategi ini menghasilkan strategi pengembangan daya tarik wisata dan pengembangan destinasi pariwisata dengan menggunakan kekuatan untuk memanfaatkan peluang.

2. Strategi Strength-Threat (S-T), dimana strategi ini menghasilkan strategi peningkatan keamanan dan kenyamanan, dalam hal ini keamanan dan kenyamanan destinasi pariwisata Kuta Lombok perlu ditingkatkan lagi yaitu dengan cara menggunakan kekuatan untuk mengatasi ancaman

3. Strategi Weakness-Opportunity (W-O), dimana strategi ini menghasilkan beberapa strategi dalam mengembangkan destinasi Kuta Lombok adalah strategi peningkatan kualitas lingkungan dan promosi destinasi pariwisata yaitu dengan meminimalkan kelemahan dalam memanfaatkan peluang.

4. Strategi Weakness-Threat (W-T), berdasarkan hasil dari analisis SWOT strategi ini menghasilkan strategi yang bisa dilakukan dalam mengembangkan destinasi pariwisata Kuta Lombok yaitu strategi pengembangan sumber daya manusia.

Kondisi Lingkungan Internal dan Eksternal Destinasi Pariwisata Kuta Lombok

1. Kondisi Lingkungan Internal Kuta Lombok

Kekuatan dan kelemahan destinasi pariwisata Kuta Lombok berdasarkan hasil obsevasi, wawancara mendalam dengan narasumber (12 narasumber) adalah:

a. Kekuatan (Strengths), yaitu semua yang dapat dikembangkan sebagai sebuah daya tarik wisata, Kekuatan Kuta Lombok diantaranya adalah keindahan alam yang terdiri dari panorama Sunrise dan sunset serta keindahan lautnya, kemudian keunikan tradisi dan budaya masyarakat local yang ergolong unik, serta sikap ramah tamah masyarakat local.

b. Kelemahan (weakness), dalam penelitian ini ditemukan beberapa penyebab lambatnya pengembangan destinasi pariwisata Kuta Lombok, diantaranya adalah kualitas maupun kuantitas sumber daya manusia (SDM) masih cukup rendah. Selain itu yang menjadi kendala dalam pengembangan Kuta Lombok juga disebabkan karena kurangnya kemauan masyarakat untuk tetap menjaga kelestarian lingkungan maupun kebersihan lingkungan sekitar, terakhir adalah karena belum tertatanya pedagang kaki lima, karena ini akan merusak pemandangan dan lingkungan.

2. Kondisi lingkungan eksternal destinasi pariwisata Kuta Lombok

a. Yang menjadi peluang dalam pengembangan destinasi pariwisata Kuta Lombok adalah kemajuan teknologi 
informasi beserta telekomunikasi yang semakin pesat perkembangannya. Semakin berkembang teknologi tehnologi tersebut akan membuat seseorang lebih mudah untuk mencari informasi dengan cepat.

b. Ancaman (Threats), salah satu yang menjadi ancaman terhadap perkembangan destinasi pariwisata Kuta Lombok adalah keamanan dan kenyamanan, sedangkan yang membuat atau mempengaruhi keamanan dan kenyamanan di Kuta Lombok adalah disebabkan karena kondisi areal parker yang masih belum terkelola dengan baik, ketersediaan fasilitas toilet umum yang masih sangat kurang memadai, perilaku agresif pedagang asongan. Kondisi seperti ini tentu akan memperburuk citra destinasi pariwisata Kuta Lombok.

\section{SIMPULAN DAN SARAN Simpulan}

Berdasarkan hasil yang didapatkan terkait strategi pengembangan destinasi pariwisata Kuta Lombok agar menjadi dalah satu destinasi pariwisata yang mempunyai daya saing yang tinggi, maka dapat ditarik kesimpulan, bahwa potensi yang di miliki oleh Kuta Lombok adalah sangat layak unuk dikembangkan. Adapun potensi-potensi tersebut adalah.

1. Potensi alam, yang meliputi pemandangan matahari terbit (sunrise) dan matahari terbenam (sunset), keindahan pantai serta lautnya dan juga perbukitan yang tersusun bagaikan benteng perbatasan yang hijau.

2. Potensi sosial budaya, yang terdiri dari budaya masyarakat seperti; upacara adat sasak, kerajinan dan kesenian tradisional, tradisi 'Bau NyaleI'" dan presean.

Sedangkan strategi yang bisa dilakukan dalam pengembangan destinasi pariwisata Kuta Lombok adalah.

1. Strategi Strenght - Opportunity (S-O) menghasilakan strategi pengembangan daya tarik wista dan strategi pengembangan destinasi pariwisata.

2. Strategi Strength - Threat (S-T) yang menghasilkan strategi peningkatan keamanan dan kenyamanan.
3. Strategi Weakness - Opportunity (W-O) menghasilkan strategi peningkatan kualitas

4. Strategi Weakness - Threat (W-T) menghasilkan strategi pengembangan sumber daya manusia.

\section{Saran}

1. Meningkatkan sumber daya mausia khususnya di sektor pariwisata sehingga pelayanan yang diberikan menjadi lebih baik secara kualitas maupun kuantitas, sosialisasi mengenai gerakan sadar wisata.

2. ditingkatkan terutama keamanan, sehingga wisatawan yang berkunjung di Kuta Lombok lebih menikmati waktu berliburnya dengan rasa nyaman, tentram dan damai. Untuk mencapai itu semua tentu memerlukan kerjasama dengan melibatkan semua elemen masyarakat, stakeholder, serta pelaku wsata.

\section{REFERENSI}

Anonim, 2013. Statistik Kepariwisataan Kabupaten Lombok Tengah.

Biro Hukum dan Komunikasi Publik. 2016. Wonderful Indonesia Dipromosikan di Word Culture Festival 2016. Diakses 19 April 2016. Tersedia pada:

www.kemenpar.go.id/asp/detil.asp? $\mathrm{c}=16 \& \mathrm{id}=3119$.

Marpaung, Happy, 2000. Pengetahuan Kepariwisataan. Bandung: Alfabeta

Rangkuti, F. 2009. Analisis SWOT Teknik Membedah Kasus Bisnis. Jakarta: PT Gramedia Pustaka Utama. 